\title{
COMPARAÇÃO DE ASPECTOS INSTITUCIONAIS NA GESTÃO DE RECURSOS HÍDRICOS EM ALGUNS PAÍSES EUROPEUS E SUA IMPLICAÇÃO PARA A GESTÃO DA BACIA DO ALTO IGUAÇU - PR
}

\author{
Enéas Souza Machado \\ Superintendência de Desenvolvimento de Recursos Hídricos e Saneamento Ambiental \\ SUDERHSA - Curitiba - PR \\ eneasm@homeshopping.com.br
}

\section{RESUMO}

O trabalho apresenta o arranjo institucional existente nos modelos de gestão de recursos hídricos do Reino Unido, França e Alemanha, e compara as seguintes características institucionais: o grau de centralização do modelo em relação ao governo central, a cobrança pelo uso da água, a relação entre gestão da água e gestão ambiental, a relação entre gestão da água e gestão do uso do solo, a convivência de funções regulatórias e executivas e o grau de participação da iniciativa privada. Finalmente, esses mesmos aspectos são comentados à luz da tentativa de implantação de um sistema de gestão de recursos hídricos para a bacia do Alto Iguaçu, na Região Metropolitana de Curitiba.

\section{INTRODUÇÃO}

A gestão de recursos hídricos vem cada vez mais assumindo um papel relevante na atualidade, por força dos crescentes conflitos que aparecem num mundo cada vez mais populoso e carente de água, matéria prima para praticamente todas as atividades humanas.

Enquanto a hidrologia e a hidráulica sempre foram feudos de engenheiros especializados que até pouco tempo desprezavam os aspectos gerenciais, a gestão da água tem atraído a atenção de várias especialidades tais como economistas, urbanistas, juristas e os ainda desconfiados engenheiros, agora intitulados engenheiros de recursos hídricos.

Como acontece com quase todo o saber técnico e científico da humanidade, a gestão de recursos hídricos veio a reboque de necessidades e conflitos, que exigiam água em maior abundância e de melhor qualidade. A questão assumiu aspectos mais graves logo após a II Grande Guerra, quando toda a Europa em reconstrução aumentava a demanda por água e poluia seriamente os cursos d'água com despejos humanos e industriais. Em alguns locais essa preocupação remonta ao início do século ou até anteriormente, como é o caso da Associação do rio Emscher, na Alemanha, criada em 1904 pelos próprios usuários, para melhorar a qualidade da água de um rio gravemente poluído.

No Brasil o tema vem suscitando discussões e tentativas de implantação da gestão desde o início da década de 80 . Podese citar como marco o Seminário internacional de 1983 promovido pelo Departamento Nacional de Águas e Energia Elétrica DNAEE, com a participação de especialistas ingleses, franceses e alemães. Por iniciativa do DNAEE, organizaram-se comitês de bacias federais, de pouco sucesso, talvez devido a seu caráter meramente consultivo, e devido a outras razões tais como envolver bacias de grande extensão e ser um sistema atrelado ao governo federal, criado de cima para baixo.

Após a Constituição de 1988, e com a demora de se definir uma lei federal de gestão (somente sancionada em janeiro de 1997), vários Estados criaram suas legislações de recursos hídricos, destacando-se o pioneirismo de São Paulo, com sua lei de 1991.

$\mathrm{Na}$ bacia do Alto Iguaçu, Região Metropolitana de Curitiba, após a cheia de 1983, por iniciativa de professores da Universidade Federal do Paraná e técnicos da então Superintendência de Recursos Hídricos 
e Meio Ambiente-SUREHMA, tentou-se implantar um sistema de gestão envolvendo as prefeituras da região do então chamado Altíssimo lguaçu. A ação, desprovida de apoio político, teve mais um caráter quixotesco; de acordo com o Dr. Nelson Luiz de Souza Pinto, emérito engenheiro hidráulico do Estado, Altíssimo só havia um que estava no Céu...

A literatura sobre 0 tema vem crescendo no mesmo ritmo com que se tenta implantar a gestão no Brasil. Destaca-se o trabalho pioneiro de Bursztyn e de Oliveira (1982), onde é apresentada a experiência de gestão das águas em sete países (Europa, Japão e Estados Unidos) e os Anais do já citado Seminário promovido pelo DNAEE (DNAEE, 1983), onde se expôs a experiência francesa, inglesa e alemã. Numa data mais recente, destaca-se o trabalho de Lanna (1993) que faz uma análise geral dos sistemas de gestão da água, concluindo pela necessidade de uma visão sistêmica que permita 0 planejamento estratégico das intervenções na bacia.

Ao nível internacional, deve-se citar o trabalho já clássico de Veiga da Cunha et. al., (1980), onde se expõe os princípios fundamentais da gestão da água, analisando a experiência européia e sua aplicação a Portugal, e a recente Comissão Eurowater, nomeada pela União Européia para estudar os diversos sistemas de gestão europeus e que culminou com um Simpósio em junho de 1995, cujos Anais constituem um verdadeiro state of the art da gestão de recursos hídricos na Europa. O presente trabalho cita extensivamente alguns dos relatórios produzidos pelo Eurowater, emitidos por Kraemer \& Jäger (1995), Rees \& Zabel (1995) e Barraqué, Berland \& Cambon (1995), a respeito da experiência alemã, inglesa e francesa, respectivamente.

O presente trabalho pretende apresentar os aspectos institucionais de três dos mais importantes sistemas de gestão da Europa, o inglês, o francês e o alemão, e o rebatimento de tais aspectos na atual tentativa de implantação de um sistema de gestão para a bacia do Alto Iguaçu (Região Metropolitana de Curitiba). Escolheu-se o sistema francês por ser um sistema já clássico, muito divulgado no Brasil, especialmente seu sistema baseado no binômio Comitê/Agência. O caso inglês também é bastante interessante: um sistema estatal de gestão e um sistema privado de operação de serviços, sistemas esses que despertam interesse no Brasil, com a onda de privatização que deve acontecer no saneamento básico brasileiro. $O$ modelo alemão é igualmente interessante, não somente pelo seu sucesso, como por poder permitir uma comparação com um modelo de uma república federativa, como o Brasil.

Além de uma descrição sucinta dos aspectos históricos e institucionais, dá-se destaque aos seguintes temas, relevantes para o sucesso do modelo brasileiro e, em especial, para o modelo que se pretende implantar no Alto Iguaçu:

- o grau de centralização do modelo, em especial em relação ao governo federal;

- a cobrança pelo uso da água: suas características, quem cobra, onde é aplicado;

- a relação entre a gestão da água e a gestão ambiental;

- a relação entre a gestão dos recursos hídricos e a gestão do uso do solo;

- a convivência de funções de gestão com funções executivas;

- o grau de participação dos usuários da água.

\section{HISTÓRICO E DESCRIÇÃO SUCINTA DOS MODELOS EUROPEUS}

Antes de se descrever os modelos institucionais, apresenta-se na Tabela 1 algumas características básicas dos três países em estudo, bem como do Estado do Paraná e da Bacia do Alto Iguaçu. O Reino Unido apresenta a menor disponibilidade hídrica per capita dos três países, função de sua pequena área, sem grandes rios ou aqüíferos. Já a França apresenta uma densidade populacional menor que a metade do Reino Unido ou Alemanha, e uma das maiores taxas de disponibilidade de recursos hídricos da Europa. A Alemanha, com uma 
Tabela 1. Características básicas dos países estudados.

\begin{tabular}{|c|c|c|c|c|}
\hline & Reino Unido & França & Alemanha & $\begin{array}{l}\text { Paraná/ } \\
\text { Alto Iguaçu }\end{array}$ \\
\hline $\begin{array}{l}\text { Divisão Político } \\
\text { Administrativa }\end{array}$ & $\begin{array}{c}\text { Rep. Unitária } \\
402 \text { distritos } \\
2000 \text { localidades }\end{array}$ & $\begin{array}{c}\text { Rep. Unitária } \\
22 \text { regiões } \\
95 \text { départm. } \\
36000 \text { localidades }\end{array}$ & $\begin{array}{l}\text { Rep. Federal } \\
16 \text { Länders } \\
11000 \text { local }\end{array}$ & \\
\hline Área $\left(\mathrm{km}^{2}\right)$ & 224.755 & 543.965 & 356.840 & $200.000 / 3.700$ \\
\hline População (milhões) & 55,5 & 56,6 & 78,5 & $10,0 / 2,0$ \\
\hline $\begin{array}{l}\text { Dens. Populacional } \\
\left(\mathrm{hab} / \mathrm{km}^{2}\right)\end{array}$ & 234 & 104 & 225 & $50 / 550$ \\
\hline $\begin{array}{l}\text { Disponib. Hídrica } \\
\left(\mathrm{m}^{3} / \text { hab/ano }\right)\end{array}$ & 2.200 & 3.600 & 2.800 & $11.700 / 1.000$ \\
\hline $\begin{array}{l}\text { Abast. Público por } \\
\text { Tipo de Fonte: } \\
\text { sup.-sub. (\%) }\end{array}$ & $70 \%-30 \%$ & $43 \%-57 \%$ & $30 \%-70 \%$ & $\begin{array}{l}80-20 \% \\
95-5 \%\end{array}$ \\
\hline
\end{tabular}

população superior à do Reino Unido, conta com uma relativa abundância de água, graças às chuvas abundantes e grandes reservas em planícies aluviais e nos lençóis subterrâneos.

O Estado do Paraná, em comparação àqueles países europeus, é riquíssimo no que tange à disponibilidade hídrica, e a Bacia do Alto Iguaçu, em função da pequena área e alta população, se encontra numa situação limite face às médias européias.

\section{Histórico e atual desenho institucional}

Inglaterra I País de Gales. O desenho institucional de gestão de águas na Inglaterra e País de Gales tem sofrido grandes transformações nas últimas décadas. Para os propósitos deste artigo, serão apenas comentadas as leis de águas de 1973 e 1989.

Em função da multiplicidade de órgãos intervenientes nas questões relativas a gestão e aproveitamento de águas, o Parlamento aprovou em dezembro de 1973 (entrou em vigor em $1^{\circ}$ abril de 1974) uma Lei de Águas que criava 10 Autoridades Regionais da Água (nove na Inglaterra e uma no País de Gales), sob a égide do governo central. Essas Autoridades Regionais possuiam amplas competências, seja na área propriamente dita de gestão (emissão de outorgas, alocação de recursos hídricos a vários usuários), seja na área de utilização de recursos hídricos (abastecimento público, coleta e tratamento de efluentes domésticos, navegação, drenagem, pesca em águas interiores e costeiras, proteção contra enchentes).

O desenho posto em prática apresentava uma grave falha conceitual, agrupando em uma mesma entidade as atividades de law enforcement e operação de serviços de saneamento básico. Na prática, as Autoridades Regionais fechavam os olhos à sua constante deficiência em atender aos padrões de qualidade ambiental que a lei preconizava.

Aquele sistema permaneceu em vigência até a introdução da nova Lei de Águas, em 1989. Segundo Kinnersley (1992), três grandes razões motivaram a alteração do sistema vigente: em primeiro lugar, o movimento neo-liberal irresistível que varreu a Inglaterra a partir do primeiro governo Thatcher e que acabou atingindo o setor de águas; em segundo lugar, a necessidade de altíssimos investimentos para modernizar e expandir o setor e a falta de recursos das 10 Autoridades estatais (segundo Cavalcanti (1993), estimava-se a necessidade de investimentos da ordem de $£ \$ 25$ bilhões até o ano 2000); e, em terceiro lugar, a óbvia constatação acima apresentada, de que a raposa tinha sido colocada como guardiã do galinheiro. 
Com o novo desenho, as 10 Autoridades Regionais foram separadas em órgãos de gestão e empresas de serviço de saneamento, estas sendo privatizadas, ficando responsáveis por $75 \%$ do abastecimento de água da Inglaterra e País de Gales. Coleta e tratamento de esgotos também passaram completamente para a alçada dessas empresas privatizadas. Paralelamente, a nova lei criou dois órgãos com funções regulatórias: a National Rivers Authority (NRA), com funções regulatórias na área de recursos hídricos e o Office of Water Services (OFWAT), que monitora as tarifas e a qualidade dos serviços das empresas, ambas vinculadas à Secretaria de Estado para o Meio Ambiente. A NRA atua de forma descentralizada, através de 10 escritórios regionais, com cerca de 6500 funcionários. Em 1995, a NRA foi fundida ao Her Majesties Inspectorate of Pollution, criando-se a Environmental Agency.

França. Após a Segunda Guerra Mundial, a França experimentou uma industrialização maciça, além da construção de redes de esgoto, não acompanhadas de respectivas estações de tratamento. Esse desenvolvimento levou a uma crescente poluição dos rios. Os engenheiros franceses, muitos treinados nos Estados Unidos, dentro da tendência micro-econômica de internalização de externalidades (custos privados repassados à sociedade), e também conhecedores do sistema de gestão de bacia no rio Ruhr, na Alemanha, propuseram a adoção do princípio poluidor-pagador, e a gestão por bacia hidrográfica, como base da nova Lei de Águas de 1964.

A Lei de 1964 constituiu-se num marco notável na história da gestão de recursos hídricos francesa, baseada num tripé: um reforço da legislação, a atuação em áreas geográficas específicas (no caso, dividindo o País em 6 grandes bacias) e a obtenção de recursos para financiar novos investimentos, especialmente, tratamento de efluentes industriais e domésticos. Outro aspecto a se destacar na lei de 1964, foi de que praticamente não se mexeu no sistema de gestão previamente existente: permaneceram as atribuições anteriormente existentes nos vários níveis de governo e uma certa dificuldade de se executar o "law enforcement". As Agências Financeiras de Bacia acabaram sendo implementadas somente a partir de 1970.

A lei de 1964 dividiu o País em 6 grandes bacias, criando, para cada uma, um Comitê da Bacia e uma Agência Financeira da Bacia (hoje chamada de Agência de Águas). Instituiu-se a redevance, cobrança pelo uso da água, que inclui a redevance de prévèlement (retirada de água) e redevance de consommation (lançamento de efluentes). A aplicação desse montante de recursos é determinada pelo Comitê e operacionalizado através da Agência. As taxas totais (taxa de captação e taxa de lançamento) montam a $6,5 \%$ das tarifas de água e esgotos.

O Comitê de Bacia é formado por $1 / 5$ de representantes do Governo Central (previamente 1/3; a diferença ficou com Associações de ecologia e lazer), 1/3 de autoridades locais e 1/3 de usuários.

Alemanha. A lei federal de Gestão das Águas na Alemanha data de 1957 (revisada em 1986). Provê uma estrutura básica para a gestão das águas, deixando o detalhamento legal e a execução para os Länder (Estados). Destaca-se também a Lei de Taxação de Efluentes, de 1976 (revisada em 1994), que define incentivos econômicos para a redução da poluição hídrica e provê recursos financeiros para medidas de proteção dos recursos hídricos.

A gestão efetiva é realizada pelos Länder, através dos escritórios regionais dos Departamentos de Água das Secretarias de Meio Ambiente.

Um exemplo notável de gestão de recursos hídricos na Alemanha é o caso do Vale do rio Ruhr: em função do grande desenvolvimento industrial e de concentração de população, criou-se uma associação compulsória, Associação do Ruhr (Ruhrverband) para a melhoria da qualidade da água, além da Associação de Barrageiros do Ruhr (Ruhrtalsperrenverein) para a construção e operação de reservatórios de regularização de vazão (as duas Associações 
foram fundidas em 1990). Essas Associações tiveram uma origem ainda anterior, em 1904, com a criação da Associação da vizinha Bacia do rio Emscher. Participam do Ruhrverband os industriais e demais usuários e as comunidades locais. A Assembléia de membros (cerca de 1500) decide sobre as taxas a serem cobradas e o plano de aplicação dos recursos. Apesar do sucesso das Associações do Emscher e do Ruhr, esse modelo não foi repetido em outras partes da Alemanha, ficando característico da região industrial da Renânia-Westfália.

\section{COMPARAÇÃO DE ASPECTOS INSTITUCIONAIS}

\author{
Os aspectos institucionais aqui \\ comentados são aqueles citados na \\ introdução desse trabalho. A comparação \\ entre os três países é apresentada na \\ Tabela 2, sobre a qual se tecem alguns \\ comentários.
}

\section{Grau de centralização em relação ao governo central}

Por ser uma república federativa, a Alemanha possui um modelo mais descentralizado: leis federais mais genéricas, complementadas com leis estaduais detalhadas, ficando a execução de gestão a cargo dos Länders, ou, melhor ainda, a cargo dos governos regionais de cada Länder. No caso dos dois outros países, o modelo inglês é certamente o mais centralizado, ficando a Agência Ambiental, através seus 10 escritórios regionais, responsável pela gestão de recursos hídricos.

\section{Cobrança pelo uso da água}

Os três países analisados cobram pelo uso da água (retirada e diluição); entretanto, somente na França os recursos são quase que integralmente utilizados para benefício de quem pagou, principalmente através da construção de estações de tratamento de efluentes. Deve-se destacar que os recursos das Agências de Água não integram o orçamento único do governo, motivo de ira dos políticos franceses. Na Alemanha, somente os recursos arrecadados pela taxação de lançamentos são diretamente aplicados em benefício aos usuários; já a taxa de uso da água financia as atividades das entidades de recursos hídricos. No Reino Unido, os recursos arrecadados fazem parte do orçamento da Agência Ambiental e são utilizados basicamente para recuperação de custos do aparato de gestão.

\section{Relação entre gestão da água e gestão ambiental}

A tendência nos três países pesquisados é aproximar cada vez mais as políticas de recursos hídricos com as ambientais, especialmente no que tange ao controle da poluição hídrica. $O$ caso mais notável talvez seja o do Reino Unido, onde a Agência Ambiental (que atua na Inglaterra e País de Gales) centraliza atividades de gestão de recursos hídricos, pesca, controle da poluição, controle de cheias e políticas de lixo urbano. Outra entidade é responsável por aspectos de Conservação da Natureza. A França continua com um sistema de gestão confuso e dividido em vários Ministérios, embora o Ministério do Meio Ambiente cada vez mais centralize tais atividades. $\mathrm{Na}$ Alemanha também se tem uma gestão integrada. O licenciamento é único no Reino Unido. Na França, o licenciamento é previsto na Lei de Licenciamento Ambiental, de 1976, para certos tipos de instalações industriais e outras atividades e também na Lei de Águas. Porém, obtida a licença ambiental, não é necessário obter a licença prevista na Lei de Águas. $\mathrm{Na}$ Alemanha, as leis também prevêem dois tipos de licenças. No caso de atividades relacionadas à utilização de recursos hídricos, há necessidade de obtenção de ambas as licenças. 


\begin{tabular}{|c|c|c|c|}
\hline Tema/País & Reino Unido & França & Alemanha \\
\hline $\begin{array}{c}\text { Grau de } \\
\text { Centralização }\end{array}$ & $\begin{array}{l}\text { - gestão executada pelos } 10 \text { escritórios } \\
\text { regionais da Agência Ambiental. }\end{array}$ & $\begin{array}{l}\text { - gestão a cargo dos Départements, que } \\
\text { agrega vários Ministérios; } \\
\text { - as Agências de Água são dissociadas do } \\
\text { aparato de gestão. }\end{array}$ & $\begin{array}{l}\text { - gestão a cargo dos Länders, através de } \\
\text { Departamentos de Recursos Hídricos das } \\
\text { Secretarias Estaduais de Meio Ambiente. }\end{array}$ \\
\hline $\begin{array}{l}\text { Cobrança } \\
\text { por abstrações } \\
\text { e lançamento } \\
\text { de efluentes }\end{array}$ & $\begin{array}{l}\text { - a cobrança é efetuada pela Agência } \\
\text { Ambiental; } \\
\text { - os recursos integram o orçamento da } \\
\text { Agência e visam recuperação de } \\
\text { custos. }\end{array}$ & $\begin{array}{l}\text { - a cobrança é efetuada pelas Agências de } \\
\text { Água; } \\
\text { - recursos estão fora do orçamento nacional; } \\
\text { - recursos visam financiar investimentos e } \\
\text { recuperar custos das Agências. }\end{array}$ & $\begin{array}{l}\text { - a cobrança por lançamento de efluentes fixada } \\
\text { por Lei Federal. Deve ser aplicado na melhoria } \\
\text { da qualidade da água; } \\
\text { - a cobrança por abstrações através de Leis } \\
\text { Estaduais; não obriga benefício direto ao } \\
\text { pagador; alguns Estados utilizam como } \\
\text { compensação financeira aos agricultores com } \\
\text { restrição de uso do solo, além de recuperações } \\
\text { de custos; } \\
\text { - ambas as cobranças efetuadas pelo Länder. }\end{array}$ \\
\hline $\begin{array}{l}\text { Gestão da Água } \\
\text { versus } \\
\text { Gestão Ambiental }\end{array}$ & $\begin{array}{l}\text { - Ministério do Meio Ambiente centraliza } \\
\text { a maioria das ações de gestão } \\
\text { ambiental e das águas, embora haja } \\
\text { participação dos Ministérios da } \\
\text { Agricultura (controle de cheias e } \\
\text { proteção costeira) e da Saúde } \\
\text { (potabilidade da água); } \\
\text { - atuação da Agência envolve recurso } \\
\text { hídrico, lançamento de efluentes } \\
\text { hídricos e gasosos, lixo urbano e } \\
\text { cheias; } \\
\text { - flora e fauna continuam em outras } \\
\text { entidades. }\end{array}$ & $\begin{array}{l}\text { - as Agências de Água e alguns órgãos } \\
\text { estatais estão ligados à Direction de l'eau, } \\
\text { do Ministério do Meio Ambiente; } \\
\text { - outros : Ministério da Saúde (potabilida-de); } \\
\text { Equipamento (navegação, controle da } \\
\text { poluição em grandes rios, esgotos e águas } \\
\text { subterrâneas em áreas urbanas); } \\
\text { Agricultura (irrigação, drenagem e esgoto } \\
\text { rural); Indústria (divide controle da poluição } \\
\text { industrial com o Ministério do Meio } \\
\text { Ambiente). }\end{array}$ & $\begin{array}{l}\text { - Ministério do Meio Ambiente mais ou menos } \\
\text { centraliza, embora haja atuação dos Ministérios } \\
\text { da Agricultura (água em áreas rurais, controle } \\
\text { de cheias e proteção costeira), dos Transportes } \\
\text { (navegação) e da Saúde (potabilidade da } \\
\text { água); } \\
\text { - gestão de recursos hídricos é parte da gestão } \\
\text { ambiental; } \\
\text { - conservação da natureza em entidade } \\
\text { separada. }\end{array}$ \\
\hline $\begin{array}{l}\text { Gestão da Água } \\
\text { versus } \\
\text { Gestão do Uso } \\
\text { do Solo }\end{array}$ & $\begin{array}{l}\text { - existe um sistema de consultas, não } \\
\text { muito efetivo, entre a Agência e as } \\
\text { Autoridades Locais responsáveis pelo } \\
\text { uso do solo. }\end{array}$ & $\begin{array}{l}\text { - os Planos de Bacia (SAGE) ainda não são } \\
\text { automaticamente traduzidos em planos } \\
\text { locais (Plans d'occupation des sols), único } \\
\text { documento com força de restrição legal. }\end{array}$ & $\begin{array}{l}\text { - existem vários tipos de Planos de Recursos } \\
\text { Hídricos feitos pelos Estados, em especial as } \\
\text { Zonas de Proteção de Águas, para mananciais } \\
\text { de abastecimento e áreas de recarga de } \\
\text { aqüíferos. }\end{array}$ \\
\hline $\begin{array}{l}\text { Funções de Gestão } \\
\text { versus } \\
\text { Funções Executivas }\end{array}$ & $\begin{array}{l}\text { - serviços de água e esgoto são de } \\
\text { competência municipal; } \\
\text { - obras de proteção contra cheias são de } \\
\text { competência da Agência. }\end{array}$ & $\begin{array}{l}\text { - serviços de água e esgoto são de } \\
\text { competência municipal; } \\
\text { - as Agências de Água não tem competência } \\
\text { de gestão; } \\
\text { - as bacias do Loire e Sena possuem } \\
\text { instituições específicas para controle de } \\
\text { cheias. }\end{array}$ & $\begin{array}{l}\text { - serviços de água e esgoto são de competência } \\
\text { municipal. }\end{array}$ \\
\hline $\begin{array}{l}\text { Grau de Participação } \\
\text { da Iniciativa Privada }\end{array}$ & - gestão estatal. & $\begin{array}{l}\text { - gestão estatal; } \\
\text { - participação no Comitê. }\end{array}$ & - gestão estatal. \\
\hline
\end{tabular}




\section{Relação entre gestão da água e gestão do uso do solo}

Não existe uma relação ideal nos três países estudados, já que gestão do uso e ocupação do solo é sempre responsabilidade das autoridades locais, enquanto que a gestão ambiental está mais ligada às autoridades regionais ou centrais. A Alemanha parece ter um sistema razoavelmente eficiente, através de vários tipos de Planos, especialmente as Zonas de Proteção de Recursos Hídricos.

\section{Relação entre funções de gestão e de execução}

Nenhum dos modelos analisados possui uma separação perfeita das atividades de gestão e de execução. Evidentemente, serviços de fornecimento de água ou esgotos, por estarem na esfera municipal, estão completamente separados das atividades de gestão. Mas outras atividades executivas estão na esfera de atuação dos entes gestores. Por exemplo, controle de cheias é função da Agência Ambiental do Reino Unido, que também atua no fomento à pesca do salmão e truta e em algumas atividades de navegação e conservação de portos.

\section{ASPECTOS INSTITUCIONAIS NA GESTÃO DE RECURSOS HÍDRICOS DA BACIA DO ALTO IGUAÇU}

Finalmente, comenta-se a relevância dos aspectos institucionais acima comentados para a gestão de recursos hídricos no Brasil e, em particular, na Bacia do Alto Iguaçu, na Região Metropolitana de Curitiba. Antes porém, um rápido comentário sobre os problemas de recursos hídricos na bacia.

A Bacia do Alto Iguaçu abrange uma área de $3.700 \mathrm{~km} 2$, com uma população de 2 milhões, dos quais 1,5 milhão em Curitiba.

O principal problema da Região Metropolitana vem a ser a devastação de seus mananciais de abastecimento, causada basicamente pela ocupação desorganizada a montante das captações. Outra questão relevante é a falta de investimentos em captação de água para abastecimento público e, especialmente, na falta de recursos para coleta e tratamento de esgotos domésticos. Também a questão de cheias, na mesma região dos mananciais, periodicamente aflige as populações ribeirinhas. Para tentar solucionar a questão conta-se até com um financiamento do Banco Mundial - Programa de Saneamento Ambiental da Região Metropolitana de Curitiba, PROSAM, que além de financiar diversas obras de saneamento ambiental, tenta propor uma solução institucional que contribua para a eliminação do problema.

A gestão das águas do Alto Iguaçu somente será eficaz se conseguir colocar, lado a lado, todos os atores envolvidos na questão, perfazendo pelo menos quatro grandes grupos: o Estado, representado pelos seus agentes: Coordenação da Região Metropolitana de Curitiba, COMEC, responsável pelo parcelamento do solo metropolitano e pelas ações do Estado na Região; a Superintendência de Desenvolvimento de Recursos Hídricos e Saneamento Ambiental, SUDHERSA, responsável pela gestão de recursos hídricos no Estado e o Instituto Ambiental do Paraná, $I A P$, órgão de meio ambiente do Estado. Em segundo lugar temos os municípios, célula base da ocupação urbana e da demanda por recursos hídricos. Em terceiro lugar os usuários da água: a Companhia de Saneamento, SANEPAR, ou outros eventuais fornecedores de abastecimento público, os industriais, os irrigantes, além de outros usuários menos significativos. Em um quarto grande grupo, usuário indireto da água, tem-se os agentes imobiliários privados, responsáveis pela apropriação do solo metropolitano, sem os quais nenhum sistema de gestão terá possibilidade de êxito.

\section{Grau de centralização face ao governo federal}

A lei federal 9.433 parece razoavelmente flexível, embora somente a sua regulamentação e a prática de alguns anos 
possam dizer até que ponto o governo federal vá descentralizar a gestão, especialmente no que diz respeito a rios de domínio da União, caso do rio Iguaçu. O modelo de gestão em estudo para o Alto Iguaçu prevê uma participação leve da União, em um Comitê de Integração para toda a bacia do Iguaçu.

\section{Cobrança pelo uso da água}

A lei federal já prevê a utilização dos recursos arrecadados em ações e obras que beneficiem diretamente os usuários, limitando uma percentagem a ser gasta na manutenção do aparato de gestão. Certamente a legislação estadual ora em preparação irá manter e reforçar tal tendência.

\section{Relação entre gestão de recursos hídricos e gestão ambiental}

O Brasil vem seguindo uma tendência mundial de centralizar as atividades de gestão ambiental, às vezes exagerando na dosagem, por exemplo, quando da criação do IBAMA, órgão único a nível federal, responsável pela execução de toda a política ambiental. Nos Estados, tem-se desde três entidades distintas (recursos hídricos, poluição industrial e conservação da natureza, caso de São Paulo e Rio de Janeiro) até um órgão único, como tentou-se no passado no Paraná, hoje com a atuação dividida em duas entidades, uma para recursos hídricos e outra para poluição e conservação da natureza. Há também que equacionar o duplo sistema de licenciamento que poderá ocorrer, com a emissão de outorgas e de licenças ambientais, em obediência às leis de recursos hídricos e à ambiental.

\section{Relação entre gestão de recursos hídricos e gestão do uso e ocupação do solo}

A exemplo da Europa, no Brasil legislar sobre o uso e ocupação do solo é competência municipal. No caso do Alto Iguaçu, uma das principais causas da poluição dos mananciais de abastecimento é a existência de loteamentos de alta densidade, legais ou não, a montante das captações. Da mesma forma, as principais vítimas de cheias periódicas no Alto Iguaçu são moradores de loteamentos situados às margens dos rios, alguns ilegais, outros legais, porém completamente inadequados. Se não se efetivar uma fórmula engenhosa de atrair os prefeitos metropolitanos e os empreendedores imobiliários para a mesa de negociação do Comitê, o modelo de gestão para o Alto Iguaçu estará fadado ao fracasso.

\section{Convivência entre funções reguladoras e executivas}

Outra tendência brasileira, acompanhando a experiência internacional, vem a ser a separação entre atividades reguladoras e de execução. No caso de serviços de água e esgotos, de alçada municipal, a separação existente ainda não é ideal. Os órgãos estaduais de recursos hídricos ou meio ambiente não se sentem exatamente à vontade para exercer uma justa função fiscalizadora junto às empresas estaduais de saneamento. A médio prazo, a situação deve melhorar com o aumento da participação da iniciativa privada no fornecimento desses serviços.

Por outro lado, os órgãos estaduais hoje ainda possuem várias funções executivas, especialmente no controle de cheias, na manutenção de viveiros de espécies nativas, etc. É preciso definir melhor um balanço adequado de tais atividades.

\section{Participação da iniciativa privada}

Finalmente, a gestão somente terá sucesso, em especial a cobrança pelo uso da água, com uma efetiva participação dos usuários, já assoberbados de impostos e taxas os mais variados. O modelo do Alto Iguaçu prevê uma participação majoritária do usuário na alocação dos recursos arrecadados. 


\section{REFERÊNCIAS}

BARRAQUÉ, B., BERLAND, J. M. e CAMBON, S. Institutional Framework for Water Resources Management in France. In: Institutional Dimensions of Water Resources ManagementComparative Analysis in the European Union and the United States, Lisbon, 178 p., jul.1012, 1995.

BURSZTYN, MARIA AUGUSTA A. E OLIVEIRA, SEBASTIÃO L., Análise da Experiência Estrangeira no Gerenciamento de Recursos Hídricos. Brasília, Secretaria Especial de Meio Ambiente/ ECT, 166p., 1982.

CAVALCANTI, JOSÉ C. da S., Panorama Internacional das Inovações e Gestão dos Sistemas de Saneamento. In: Os Desafios do Saneamento Ambiental, São Paulo, Caixa Econômica Federal/FUNDAP, São Paulo, 16p., 1993.

DEPARTAMENTO NACIONAL DE ÁGUAS E ENERGIA ELÉTRICA, Anais do Seminário Internacional de Gestão de Recursos Hídricos, 2v., Brasília, 1983.

KINNERSLEY, DAVID, Privatization and the Water Environment in England, In: Country Experience with Water Resources Management. Washington, World Bank, (World Bank Technical Paper 175), 213 p., 1992.

KRAEMER, R. A, JÄGER, F. Institutional Framework for Water Resources Management in Germany. In: Institutional Dimensions of Water Resources Management - Comparative Analysis in the European Union and the United States, Lisbon, 196p., jul.10-12, 1995.

LANNA, ANTONIO EDUARDO, Gerenciamento de Recursos Hídricos Conceitos, Princípios e Aplicações no Brasil. Porto Alegre, Universidade Federal do Rio Grande do Sul/Instituto de Pesquisas Hidráulicas, (Recursos Hídricos, 29), 70p., 1993.

REES, Y. e ZABEL, T. Institutional Framework for Water Resources Management in the United Kingdom. In: Institutional Dimensions of Water Resources Management - Comparative Analysis in the European Union and the United States, Lisbon, 207p., jul.10-12, 1995.

VEIGA DA CUNHA, L; GONÇALVES, A. S; de FIGUEIREDO, V. A; LINO, M, A Gestão da Água. Princípios Fundamentais e sua Aplicação em Portugal. Lisboa, Fundação Calouste Gulbenkian, 697p., 1980.

\section{Comparison of Institutional Aspects of Water Resources Management in Some European Countries and its Relationship for the Auto Iguaçu River Basin Management}

\section{ABSTRACT}

The paper presents the institutional arrangements of the water resources management models for the United Kingdom, France and Germany, comparing the following characteristics: the degree of centralization vis a vis the central government, the abstraction and effluent charges, the relationship between water management and environmental management, the relationship between water management and land use management, the relationship between regulatory and executive functions and the degree of participation of water users. Finally, these same aspects are reviewed taking into account the attempt of implementing a water resources management system for the Alto Iguaçu River Basin, in the Metropolitan Region of Curitiba. 